\title{
Nowcasting Aircraft Icing Conditions in the Presence of Multilayered Clouds Using Meteorological Satellite Data
}

\author{
Douglas A. Spangenberg ${ }^{1}$, Patrick Minnis ${ }^{2}$, William L. Smith ${ }^{2}$, Fu-Lung Chang ${ }^{1}$ \\ ${ }^{1}$ Science Systems and Applications, Inc., Hampton, VA, USA \\ ${ }^{2}$ NASA Langley Research Center, Hampton, VA, USA
}

\begin{abstract}
Cloud properties retrieved from satellite data are used to diagnose aircraft icing threat in single layer and multilayered ice-over-liquid clouds. The algorithms are being applied in real time to the Geostationary Operational Environmental Satellite (GOES) data over the CONUS with multilayer data available over the eastern CONUS. METEOSAT data are also used to retrieve icing conditions over western Europe. The icing algorithm's methodology and validation are discussed along with future enhancements and plans. The icing risk product is available in image and digital formats on NASA Langley's Cloud and Radiation Products web site, http://wwwangler.larc.nasa.gov.
\end{abstract}

\section{INTRODUCTION}

Super-cooled clouds constitute a significant threat to the safety of air traffic because they can cause catastrophic icing of aircraft wings and airframe. Considerable effort has been devoted to detecting super-cooled clouds and retrieving properties such as cloud-top height, droplet effective radius (Re) and liquid water path (LWP) using meteorological satellite data in real time. The results have proven valuable for nowcasting icing conditions during daytime in the absence of upper-level clouds that obscure the super-cooled clouds [1]. Moreover, they have been used in numerical weather prediction (NWP) models and in more complex icing diagnosis and forecasts that employ NWP output and pilot reports. Because icing conditions are most common during the short days of winter and often occur in multilayered baroclinic systems, it is important to learn as much as possible about the presence of potential icing clouds in those conditions. In this paper, a visible infrared solar-infrared split window technique (VISST) and 3-channel infrared technique are used for day and night conditions, respectively to get cloud properties needed to determine icing [2]. Also, a new multilayer cloud detection and retrieval system is employed to aid the detection of lower level icing clouds and their properties in ice-cloud over watercloud systems $[3,4]$. The methods are tested using data from the GOES-12 satellite and verified using pilot icing reports (PIREPS) and ground-based data.

\section{METHODOLOGY}

Icing threat depends on the presence super-cooled liquid water (SLW), liquid water content, droplet size distribution and temperature profile in the cloud. Satellite retrievals of cloud properties can provide similar data: cloud effective temperature (Te), cloud top phase, liquid water path (LWP), and effective droplet radius (Re). The satellite icing detection method was developed by comparing these variables to pilot icing reports. It is based primarily on the cloud Te and LWP retrievals. Figure 1 shows the relationship between satellite icing probability and LWP for two values of Re. Icing probability increases with LWP and is somewhat higher for larger liquid droplets. The fit was developed by comparing satellite cloud retrieval data with PIREP reports for matched data points from 2006-2008 over the continental US. In the satellite icing algorithm, the 40 and $70 \%$ icing probability values define the divisions between low, moderate and high icing probabilities. Also, for LWP above 488 gm-2, moderate to severe icing intensity is defined with light icing for liquid water paths below this value.

The satellite single layer technique is dependent only on the cloud particles at cloud top and works well at identifying icing conditions for low-level stratus as is often produced by the Great Lakes. These clouds typically have liquid droplets at the tops as seen by the satellite and at the same time usually have snow reported in the surface observations. The multilayer technique works best to separate these low levels stratus cloud systems apart from overlying cirrus clouds. For a cloud to be identified as multilayer, it has to have ice Page 1 of 6 
cloud on top with SLW or plain liquid below. There can also be ice crystals imbedded in the bottom part of the low-level cloud, which is technically a mixed phase cloud. The satellite icing algorithm is applied to either single layer clouds or to the low layer for multilayer clouds.

The satellite icing detection method is limited by optically thick ice clouds where it is not possible to determine the extent to which SLW exists within the underlying clouds. However, we determined that most of the optically thick cases are associated with convection or mid-latitude cyclones and they will nearly always have a layer where SLW exists with an icing threat. Due to the lack of visible channel data, the satellite icing detection methods will be less accurate at night; no attempt is made to separate light and moderate-heavy icing situations. The results and validation presented here are focused on daytime conditions, defined by solar zenith angles $>82^{\circ}$.

\section{RESULTS}

The GOES-12 image at 19:45 UTC 2010 Mar 15 in Fig. 2 shows a comparison of single-layer and multilayer icing. In the RGB image (Fig. 2a) there is a large storm system just off the US Mid-Atlantic coast, with ice clouds (blue) observed along side low-level clouds (peach). The extent of indeterminate areas of the VISST single layer algorithm shown in white in Fig. $2 \mathrm{~b}$ are greatly reduced when looking at the multilayer icing image in Fig. 2d. Also, the icing appears to be well detected in multilayer areas. This can be seen by the comparing the colored areas in the multilayer cloud image in Fig. $2 \mathrm{c}$ with the PIREP reports plotted on Fig. 2d.

For nighttime, the icing threat is not given a probability or intensity because the satellite retrievals are not as precise at night; they rely heavily on the GOES visible channel data. Figure 3 shows images of icing at night over the eastern USA, valid at 23:15 UTC 2010 Mar 15. It shows the same basic features as the previous daytime image in Fig. 2 taken 3.5 hours earlier. The terminator can be seen by the edge of pink cutting through the eastern US. Multilayer clouds are observed over much of the Mid-Atlantic and Northeastern parts of the US (Fig. 3c). Using the multilayer algorithm increases the area of icing detected over the northeastern part of the US, which can be seen by comparing the extent of the blue area of Figs. 3b, d. The icing occurring in that area is confirmed by the PIREPS of positive icing plotted on Fig. 3d.

A major concern with the single layer VISST algorithm is false positive icing detection where SLW is retrieved due to a cold thin cirrus shield above an above freezing liquid cloud layer. The multilayer algorithm was able to partition it into ice cloud and water cloud below with low layer $\mathrm{T}>273 \mathrm{~K}$. The multilayer algorithm eliminated false positive icing detected over Cleveland, $\mathrm{OH}$ in $10 \%$ of 40600 cases examined from 2005-2009.

\section{VALIDATION}

To ensure that the multilayer algorithm is, in fact, identifying multilayer clouds where it is supposed to, Chang et al. (2010) compared satellite data to ground based actively remote sensed cloud data from the Department of Energy Atmospheric Radiation Measurement site in northern Oklahoma using May-Aug 2009 data [5]. They find that multilayer clouds are in agreement with the ground-based data in $80 \%$ of 4000 images examined. For disagreement with the ground site data, the satellite tended to underestimate multilayer clouds.

For validating the multilayer icing algorithm, GOES-12 and PIREPS data from 11 Feb-31 Mar 2010 were used. For the following statistics, satellite positive icing occurs if at least one icing pixel is found within 20-km of the PIREP. For over 3900 matching samples in the daytime, the skill in satellite detection is high when only the single-layer algorithm is run, however, $28 \%$ of these cases cannot be determined because of thick overlying ice clouds. Including the indeterminate satellite cases results in a $72 \%$ probability of detecting positive icing (PODp). After using both single and multilayer algorithms, less than $1 \%$ of cases cannot be determined because of overlying high ice clouds and the PODp is near 99\%. When positive icing was identified by both satellite and PIREPS, two intensity categories of light and moderate-heavy agreed $57 \%$ of the time. For both single layer and combined single layer and multilayer algorithms, the probability of detecting negative icing (PODn) is only near $6 \%$ because pilots tend to only report positive icing events or in situations where icing could be expected. In the 1269 cases examined at night, for solar zenith angles $>82^{\circ}$, the PODp score increases from 74 to $87 \%$ when the satellite multilayer algorithm output is included.

Considering the dominant icing type for $8-\mathrm{km}$ pixels within $20-\mathrm{km}$ of the pilot icing reports, the agreement between single layer GOES and PIREPS for positive icing reports is $52 \%$. The other significant category is for indeterminate GOES icing with positive PIREP icing, which was found in $36 \%$ of over 3900 samples. The results are summarized in Table 1 . When multilayer satellite data are included, most of the indeterminate cases where thick cirrus was present and icing could not be identified by the single layer algorithm were actually positive icing events. The indeterminate cases are reduced to just $2 \%$ with inclusion of the multilayer

Page 2 of 6

SAE International Conference on Aircraft and Engine Icing and Ground Deicing, Chicago, IL, June 13-17, 2011 
algorithm's low layer data. This raises the satellite and PIREP positive icing agreement to $86 \%$ (Table 2). When the single layer VISST algorithm reports optically thick ice, pilots normally report icing somewhere inside the column and these clouds tend to be multilayer with positive icing seen by the multilayer algorithm.

\section{SUMMARY}

The satellite-based algorithms presented here can be used in real time to diagnose areas of icing for pilots to avoid. They use LWP and $\mathrm{Te}$ and to a small extent, Re to get icing probability and intensity. There is only one value of icing representative of the mean conditions expected within the icing layer. The algorithms perform best for sunlit conditions where uniform stratus clouds exist, with or without a cirrus layer above. The multilayer algorithm is intended for ice-over-liquid layer cloud systems only; it cannot be applied to 2 liquid layers or 2 ice layers. The combined satellite single and multilayer algorithms detected $86 \%$ of positive icing conditions with a very low amount of indeterminate pixels for Feb-Mar 2010 matched PIREP cases over the continental US.

For the next major update to satellite icing detection, the freezing level is determined from NWP model analyses and the satellite LWP is scaled to represent the part of the total cloud that is sub-freezing. This reduces the actual satellite icing threat since Te may be just below freezing with the bulk of the cloud being above freezing. The satellite base and top heights corresponding to the icing layer will also be provided. Because PIREPS are often subjective and have navigation errors, cloud parameters derived from the NASA Glenn Icing Remote Sensing System (NIRSS) deployed at NASA Glenn Research Center in Cleveland, Ohio will be used to further evaluate the satellite multilayer icing algorithm where cirrus clouds exist between the satellite and the SLW layer. Both PIREPS and NIRSS data will be examined along with the satellite results to further assess negative satellite icing.

\section{REFERENCES}

[1] Minnis, P., W.L. Smith Jr., L. Nguyen, D.A. Spangenberg, P.W. Heck, R. Palikonda, J.K. Ayers, C. Wolff, and J.J. Murray, 2004: Near-real time cloud properties and aircraft icing indices from GEO and LEO satellites. Earth Observing Systems IX Conf., International Symposium on Optical Science and Technology, SPIE $49^{\text {th }}$ Annual Meeting, Denver, CO 2-6 Aug. [2] Minnis, P., S. Sun-Mack, D.F. Young, P.W. Heck, D.P. Garber, Y. Chen, D.A. Spangenberg, R.F. Arduini, Q.Z. Trepte, W.L. Smith, Jr., J.K. Ayers, S.C. Gibson, W.F. Miller, V. Chakrapani, Y. Takano, K-N Liou, and Y. Xie, 2010: CERES Edition-2 cloud property retrievals using TRMM VIRS and Terra and Aqua MODIS data, Part I: Algorithms. Accepted for pub, IEEE Trans. Geosci. Remote Sens.

[3] Chang, F-L and Z. Li, 2005: A new method for detection of cirrus overlapping water clouds and determination of their optical properties. J. Atmos. Sci., 62, 3993-4009.

[4] Chang, F-L, P. Minnis, B. Lin, R. Palikonda, M. Khaiyer, and S. Sun-Mack, 2008: Retrieving cloud properties for multilayered clouds using simulated GOES-R data. AMS 5th GOES Users' Conference, New Orleans, LA, January 23-24, CDROM, P1.69.

[5] Chang, F-L, P. Minnis, J. K. Ayers, M. Khaiyer, and R. Palikonda, 2010: Using ARM data to evaluate and improve multilayer cloud property retrievals from GOES-East data. Second Science Team Meeting of the Atmospheric System Research (ASR) program San Antonio, TX Mar 28-Apr 1.

\section{CONTACT INFORMATION}

Douglas Spangenberg, 1 Enterprise Pkwy, STE 200, Hampton, VA 23666, email: Douglas.A.Spangenberg@nasa.gov

\section{ACKNOWLEDGMENTS}

This work was funded by the NASA Applied Sciences Program and the NOAA GOES-R Program.

Page 3 of 6

SAE International Conference on Aircraft and Engine Icing and Ground Deicing, Chicago, IL, June 13-17, 2011 
Table 1. Comparison of single-layer satellite and PIREP icing, daytime, Feb 11-Mar 31 2010. Number of samples is 3917. The + is for positive icing, - is for negative icing and I is for indeterminate satellite icing.

\begin{tabular}{|l|l|}
\hline SAT,+ PIREP + & $52.2 \%$ \\
\hline SAT,+ PIREP - & $4.8 \%$ \\
\hline SAT -, PIREP - & $1.0 \%$ \\
\hline SAT -, PIREP + & $3.0 \%$ \\
\hline SAT I, PIREP + & $35.7 \%$ \\
\hline SAT I, PIREP - & $3.3 \%$ \\
\hline
\end{tabular}

Table 2. Comparison of satellite and PIREP icing, daytime, Feb 11-Mar 31 2010. Number of samples is 3917. The + is for positive icing, - is for negative icing and I is for indeterminate satellite icing. The satellite result is for single and multi layer data combined.

\begin{tabular}{|l|l|}
\hline SAT,+ PIREP + & $85.6 \%$ \\
\hline SAT,+ PIREP - & $7.9 \%$ \\
\hline SAT -, PIREP - & $1.1 \%$ \\
\hline SAT -, PIREP + & $3.8 \%$ \\
\hline SAT I, PIREP + & $1.6 \%$ \\
\hline SAT I, PIREP - & $0.2 \%$ \\
\hline
\end{tabular}

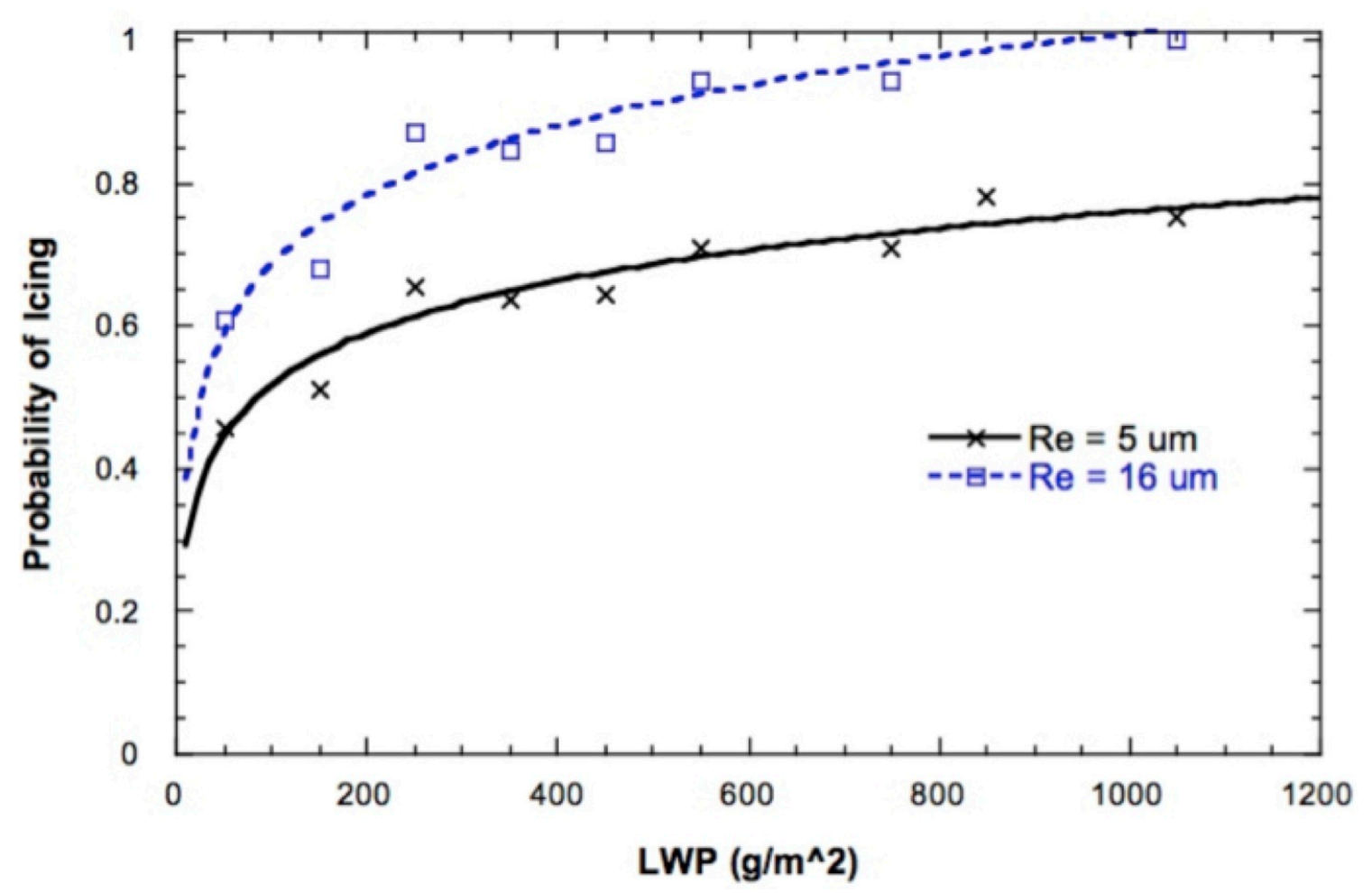

Figure 1. Variation of satellite icing probability with LWP for two liquid droplet size distributions.

Page 4 of 6 


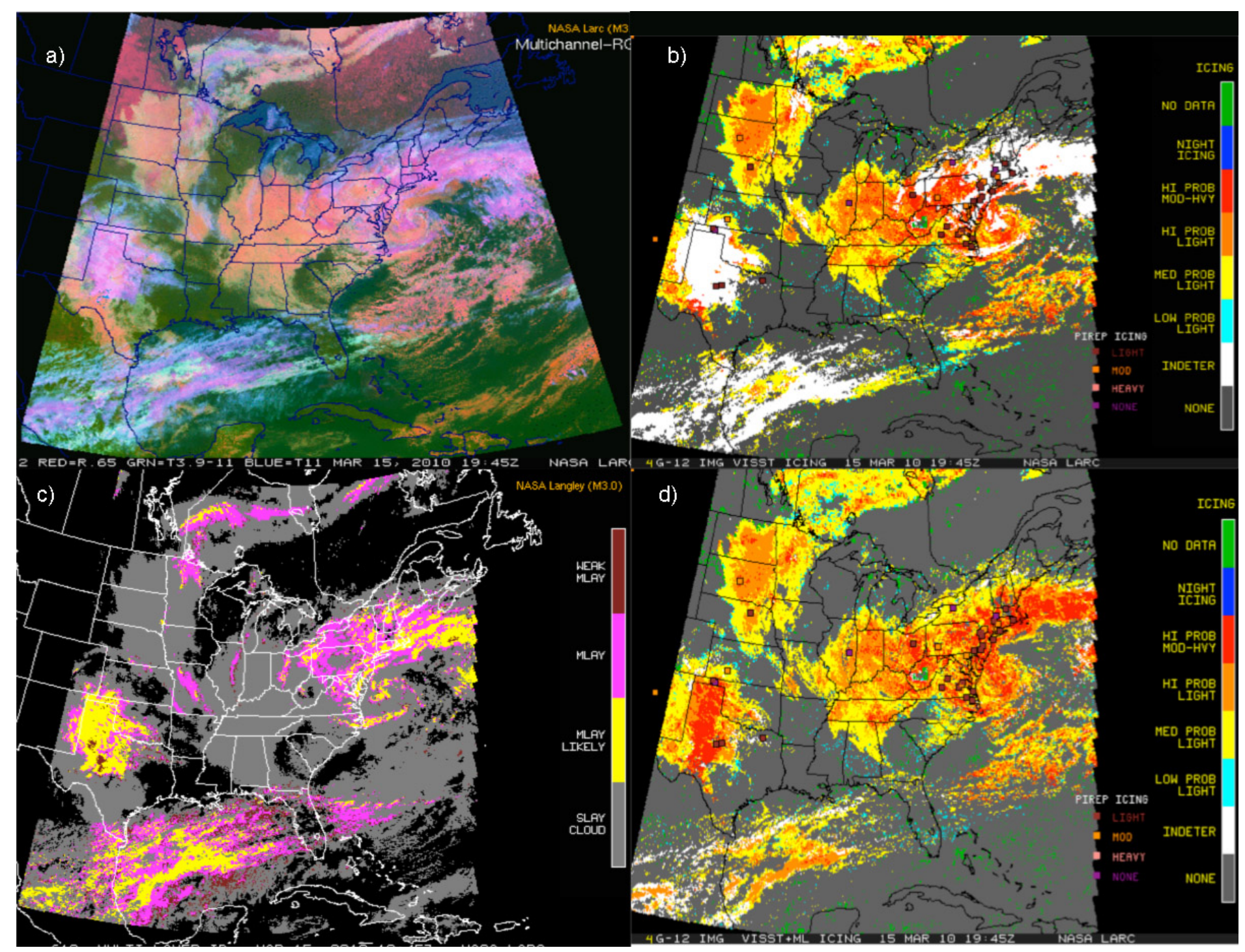

Figure 2. Satellite icing diagnosis for GOES-12 valid 15 Mar 2010 19:45 UTC. (a) shows the 3-channel composite; red=0.65 $\mu \mathrm{m}$, green $=B T D$ 3.9-10.7 $\mu \mathrm{m}$ and blue $=10.7 \mu \mathrm{m}$. (b) is the icing image from the single-layer algorithm, (c) shows the multilayer mask and (d) is the icing from combined single-layer and multilayer algorithms.

Page 5 of 6

SAE International Conference on Aircraft and Engine Icing and Ground Deicing, Chicago, IL, June 13-17, 2011 


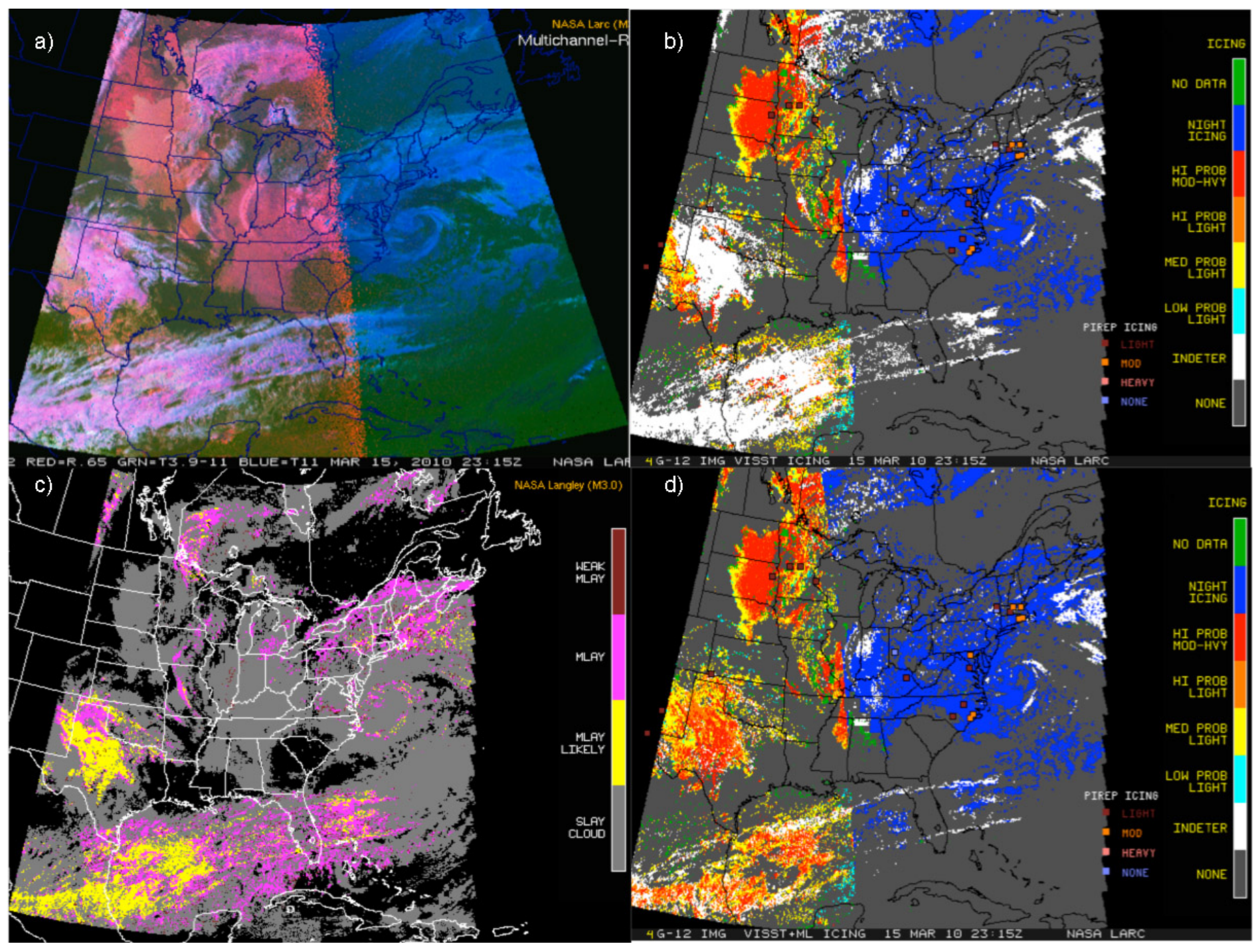

Figure 3. Satellite icing diagnosis for GOES-12 valid 15 Mar 2010 23:15 UTC. (a) shows the 3-channel composite; red=0.65 $\mu \mathrm{m}$, green $=B T D$ 3.9-10.7 $\mu \mathrm{m}$ and blue $=10.7 \mu \mathrm{m}$. (b) is the icing image from the single-layer algorithm, (c) shows the multilayer mask and (d) is the icing from combined single-layer and multilayer algorithms. 